СавУщик А. И., САРИЛов М. Ю.

РАЗРАБОТКА МЕТОДА ПОДГОТОВКИ ВЫСОКОВЯЗКИХ БИТУМИНОЗНЫХ НЕФТЕЙ ДЛЯ ТРАНСПОРТИРОВКИ ПО СУЩЕСТВУЮЩИМ НЕФТЕПРОВОДАМ

Савущик А. И., Сарилов М. Ю.

A. I. Savushchik, M. Yu. Sarilov

РАЗРАБОТКА МЕТОДА ПОДГОТОВКИ ВЫСОКОВЯЗКИХ БИТУМИНОЗНЫХ НЕФТЕЙ ДЛЯ ТРАНСПОРТИРОВКИ ПО СУЩЕСТВУЮЩИМ НЕФТЕПРОВОДАМ

\title{
DEVELOPMENT OF HIGH VISCOSITY OIL PREPARATION METHOD FOR TRANSPORTATION THROUGH EXISTING OIL PIPELINE
}

Савущик Александр Иванович - магистрант кафедры «Машины и аппараты химических производств» Комсомольского-на-Амуре государственного технического университета (Россия, г. Комсомольск-наАмуре). E-mail: sashacolmar@mail.ru.

Mr. Aleksandre I. Savushchik - Master's degree student, Department of Chemical Industry Machinery and Equipment, Komsomolsk-on-Amur State Technical University (Russia, Komsomolsk-on-Amur). E-mail: sashacolmar@mail.ru.

Сарилов Михаил Юрьевич - доктор технических наук, профессор кафедры «Машины и аппараты химических производств» Комсомольского-на-Амуре государственного технического университета (Россия, г. Комсомольск-на-Амуре). E-mail: sarilov@knastu.ru.

Mr. Mikhail Yu. Sarilov - D.Sc. in Engineering, Head of the Department of Chemical Industry Machinery and Equipment, Komsomolsk-on-Amur State Technical University (Russia, Komsomolsk-on-Amur). E-mail: sarilov@knastu.ru.

Аннотация. В статье представлены результаты экспериментов по обработке нефти СВЧ излучением и выбран наиболее оптимальный режим воздействия излучения.

Summary. In the article, the results of the experiment of microwave radiation processing of oil are presented. The best mode of the radiation exposure is chosen.

Ключевые слова: вискозиметр, излучение, вязкость.

Key words: viscometer, radiation, viscosity.

УДК 665.63(07)

\section{Введение}

Пропускная способность и экономическая эффективность нефтепровода зависят от свойств перекачиваемой по нему нефти. Основным препятствием для обеспечения необходимой скорости перекачивания является вязкость. Снижение вязкости перекачиваемой нефти уменьшает гидравлическое сопротивление трубопроводной сети, что уменьшает энергозатраты на перекачку. В районах добычи нефти с низкой температурой окружающей среды вязкость перекачиваемой жидкости достигает таких значений, что энергозатраты на перекачку значительно повышают стоимость добываемой нефти, а в некоторых случаях делают ее перекачку практически невозможной. Для увеличения эффективности процесса транспортировки вязкие и высоковязкие нефти подвергают предварительной обработке. Известно множество способов обработки нефти с целью уменьшения ее вязкости: термический нагрев, создание эмульсии нефти в воде при помощи веществэмульгаторов, воздействие на жидкость различными видами электромагнитного излучения и их комбинациями, обработка нефти с помощью ультразвуковых колебаний высокой интенсивности. Мы решили остановиться на обработке сверхвысокочастотным (СВЧ) излучением. Нефть была предоставлена лабораторией Астраханского нефтеперерабатывающего завода для подготовки к научной конференции молодых специалистов на Комсомольском нефтеперерабатывающем заводе. Она обладает высокой вязкостью. Ее характеристики представлены в табл. $1-2$. 


\begin{tabular}{|c|c|}
\hline 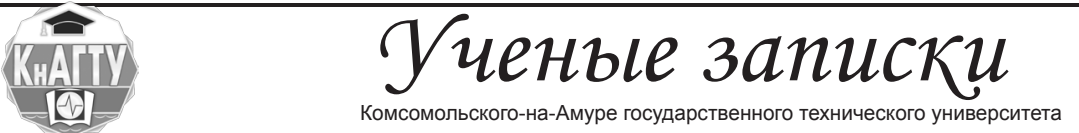 & V(0) \\
\hline \multirow{2}{*}{\multicolumn{2}{|c|}{ Характеристики исходного материала }} \\
\hline & \\
\hline \multicolumn{2}{|r|}{ Значения } \\
\hline Плотность сепарированной нефти при $20^{\circ} \mathrm{C}$, кг $/ \mathrm{m}^{3}$ & $917-933$ \\
\hline $\begin{array}{l}\text { Вязкость нефти кинематическая, сСт } \\
\text { при } 50^{\circ} \mathrm{C} \\
\text { при } 80^{\circ} \mathrm{C}\end{array}$ & $\begin{array}{l}413,51-458,65 \\
101,39-204,54\end{array}$ \\
\hline $\begin{array}{l}\text { Вязкость нефти динамическая, мПа*с } \\
\text { при } 50^{\circ} \mathrm{C} \\
\text { при } 80^{\circ} \mathrm{C}\end{array}$ & $\begin{array}{l}371,22-420,24 \\
88,87-172,79 \\
\end{array}$ \\
\hline \multirow{2}{*}{\multicolumn{2}{|c|}{ Физико-химические характеристики исходного материала }} \\
\hline & \\
\hline \multicolumn{2}{|l|}{ в нефти, масс. $\%$} \\
\hline - парафина & $6,01-6,97$ \\
\hline - смол силикагельных & $21,44-29,18$ \\
\hline - асфальтенов & $0,76-1,16$ \\
\hline - серы & $1,19-1,32$ \\
\hline - воды & $0,21-0,23$ \\
\hline - мех. примесей & 0,04 \\
\hline Температура застывания, ${ }^{\circ} \mathrm{C}$ & $+25-28$ \\
\hline Температура плавления парафина, ${ }^{\circ} \mathrm{C}$ & $+59-63$ \\
\hline \multicolumn{2}{|l|}{ Фракционный состав нефти по ГОСТ РЕНИСО 3405-2007 } \\
\hline Начало кипения, ${ }^{\circ} \mathrm{C}$ & $86-95$ \\
\hline Температурные пределы выкипания фракций, ${ }^{\circ} \mathrm{C}$ & Выход, об. \% \\
\hline до 100 & $1-5$ \\
\hline до 150 & $5-12$ \\
\hline до 200 & $10-17$ \\
\hline до 250 & $16-22$ \\
\hline до 300 & $21-29$ \\
\hline \multicolumn{2}{|c|}{$\begin{array}{l}\text { Приведенные выше данные свидетельствуют о том, что нефть относится к классу тяжелых } \\
\left(933 \text { кг } / \mathrm{m}^{3}\right) \text {, высоковязких }\left(458 \text { сСт при }+50{ }^{\circ} \mathrm{C}\right) \text {, с содержанием смол и асфальтенов более } 30 \text { \% и } \\
\text { температурой застывания }+25^{\circ} \mathrm{C} . \text { Вязкость }- \text { одно из явлений переноса, свойство текучих тел ока- } \\
\text { зывать сопротивление перемещению одной их части относительно другой. В результате работа, } \\
\text { затрачиваемая на это перемещение, рассеивается в виде тепла. Механизм внутреннего трения в } \\
\text { жидкостях и газах заключается в том, что хаотически движущиеся молекулы переносят импульс } \\
\text { из одного слоя в другой, что приводит к выравниванию скоростей - это описывается введением } \\
\text { силы трения. Очевидно, что у пользователей недр, ведущих разработку залежей нефти с высокой } \\
\text { вязкостью, а также и залежей нефти с высоким содержанием парафинов, возникают определенные } \\
\text { технологические трудности и связанные с ними значительные финансовые затраты как на этапе } \\
\text { подготовки товарной нефти на промысле, так и при дальнейшей её транспортировке к потребителю. }\end{array}$} \\
\hline \multicolumn{2}{|c|}{$\begin{array}{l}\text { Методика исследований } \\
\text { Для проведения эксперимента была разработана модель установки, в которую входили сле- } \\
\text { цие приборы: термометр; вискозиметр; магнетрон с возможностью регулирования мощности; } \\
\text { яетр; секундомер; колба. }\end{array}$} \\
\hline
\end{tabular}


САВУЩИК А. И., САРИЛОВ М. Ю.

РАЗРАБОТКА МЕТОДА ПОДГОТОВКИ ВЫСОКОВЯЗКИХ БИТУМИНОЗНЫХ НЕФТЕЙ ДЛЯ ТРАНСПОРТИРОВКИ ПО СУЩЕСТВУ ЮЩИМ НЕФТЕПРОВОДАМ

Исходная нефть помещалась в колбу, после этого производился отбор нулевой пробы. Затем выставляли необходимую мощность СВЧ воздействия и включали источник электромагнитного поля СВЧ (см. рис. 1).

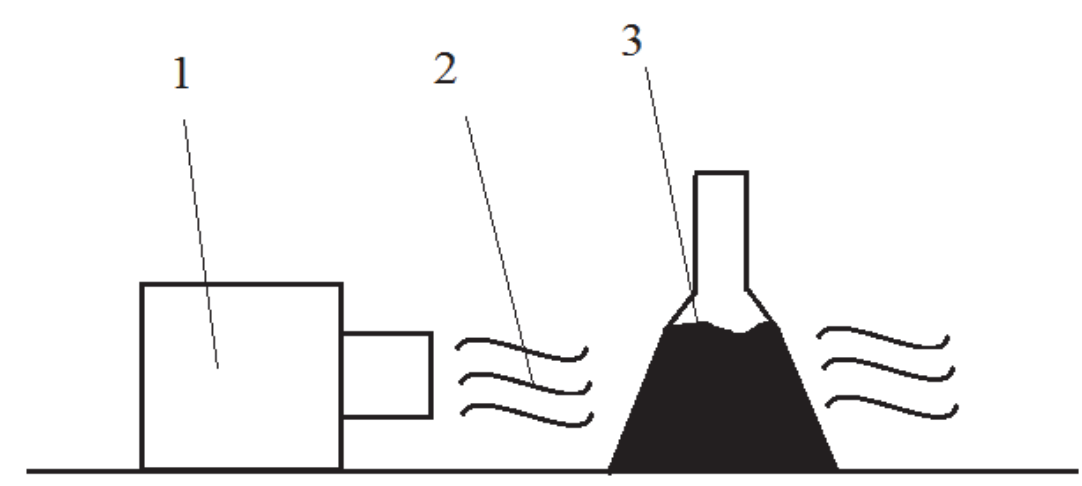

Рис. 1. Экспериментальная модель лабораторной установки:

1 - магнетрон; 2 - СВЧ излучение; 3 - колба с нефтью

Максимальное время СВЧ обработки составляло 20 мин. Контроль температуры производился с помощью термометра. Значения фиксировались и заносились в табл. 3.

Таблица 3

Температура при разных мощностях СВЧ воздействия

\begin{tabular}{|c|c|}
\hline Мощность СВЧ излучения, Вт & Температура, ${ }^{\circ} \mathrm{C}$ \\
\hline 100 & 101 \\
\hline 200 & 108 \\
\hline 500 & 118 \\
\hline 750 & $120 *$ \\
\hline 900 & $121 * *$ \\
\hline $\begin{array}{l}\text { * время СВЧ обработки составля } \\
\text { ** время СВЧ обработки составЈ }\end{array}$ & \\
\hline
\end{tabular}

Плотность полученных проб нефти определялась с помощью ареометра. За температуру застывания была принята та температура, при которой уровень в колбе не изменялся в течение 1 мин, пока колба была наклонена на 45 градусов. Результаты анализов заносились в табл. 4.

Таблица 4

Результаты сравнительных анализов определения плотности и температуры застывания

\begin{tabular}{|c|c|c|c||}
\hline \multicolumn{2}{|c|}{ Плотность, кг $/ \mathrm{M}^{3}$} & \multicolumn{2}{c|}{ Температура застывания, ${ }^{\mathbf{0}} \mathrm{C}$} \\
\hline Нулевая проба & После СВЧ воздействия & Нулевая проба & После СВЧ воздействия \\
\hline 890 & 890 & более 18 & менее 6 \\
\hline 895 & 895 & более 18 & менее 6 \\
\hline 895 & 900 & более 18 & менее 6 \\
\hline 890 & 890 & более 18 & не более 0 \\
\hline 895 & 895 & более 18 & не более 0 \\
\hline
\end{tabular}




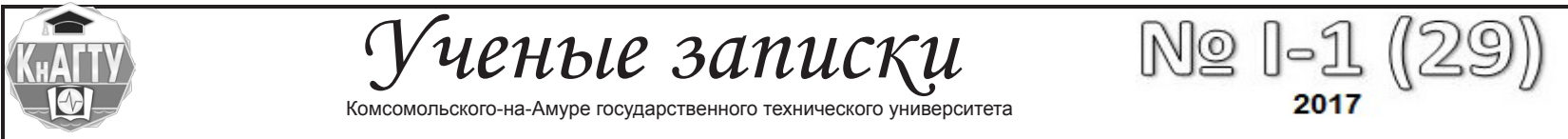

Результаты исследований

Результаты анализа плотности нефти показывают, что 30-минутное воздействие СВЧ излучения при мощностях от 100 до 900 Вт не оказывает заметного влияния на изменение плотности, в связи с этим было принято решение в дальнейших экспериментах не производить анализы плотности нефти.

Сравнительный анализ результатов измерения температуры застывания образцов обработанной и исходной нефти показывает, что 30-минутная СВЧ обработка при мощностях от 100 до 900 Вт приводит к снижению температуры застывания, что косвенно указывает на уменьшение вязкости нефти. Показатели значений температуры застывания снижаются с увеличением мощности СВЧ воздействия и достигают минимального значения при мощности более 500 Вт.

Во избежание роста давления при обработке с мощностями СВЧ воздействия 700 и 900 ВТ время обработки сокращали до 15 и 10 мин соответственно, при этом значения показателей температуры застывания обработанных образцов не ухудшались.

У всех обработанных образцов нефти было обнаружено временное до 2 - 4 дней сохранение текучего состояния с достигнутой температурой застывания, которое через 5 - 7 дней пропадало, при этом нефть возвращалась в исходное состояние с температурой застывания более $18{ }^{\circ} \mathrm{C}$.

Таким образом, приняв во внимание снижение температуры застывания при СВЧ обработке с большими мощностями при меньшей длительности воздействия, было принято решение исследовать влияние длительности СВЧ обработки на 900 Вт мощности.

Определение влияния длительности СВЧ обработки на показатели температуры застывания нефти. Исходная нефть помещалась в колбу, после этого производился отбор нулевой пробы. Затем выставляли мощность СВЧ воздействия 900 Вт и включали источник электромагнитного поля СВЧ на время, определенное в табл. 5. Контроль температуры производился с помощью термометра.

Таблица 5

Температура при мощности 900 Вт СВЧ облучения при различной длительности СВЧ обработки

\begin{tabular}{|c|c|}
\hline Время, мин & Tемпература, ${ }^{\circ} \mathrm{C}$ \\
\hline 0 & 21 \\
\hline 0,5 & 81 \\
\hline 1 & 82 \\
\hline 1,5 & 83 \\
\hline 2 & 84 \\
\hline
\end{tabular}

По завершении СВЧ обработки производился отбор проб. Результаты анализов полученных образцов нефти заносили в табл. 6.

Таблица 6

Результаты сравнительных анализов определения температуры застывания

\begin{tabular}{||c|c|}
\hline \multicolumn{2}{|c|}{ Температура застывания, ${ }^{\circ} \mathrm{C}$} \\
\hline Нулевая проба & После СВЧ обработки \\
\hline более 18 & менее 6 \\
\hline более 18 & менее 6 \\
\hline более 18 & не более 0 \\
\hline более 18 & не более 0 \\
\hline \multicolumn{2}{|c}{} \\
\hline
\end{tabular}


САвУЩИк А. И., САРИЛОв М. Ю.

РАЗРАБОТКА МЕТОДА ПОДГОТОВКИ ВЫСОКОВЯЗКИХ БИТУМИНОЗНЫХ НЕФТЕЙ ДЛЯ ТРАНСПОРТИРОВКИ ПО СУЩЕСТВУЮЩИМ НЕФТЕПРОВОДАМ

Кратковременная СВЧ обработка нефти при мощности 900 Вт не приводит к существенному росту показателей температуры.

Сравнительный анализ результатов измерения температуры застывания образцов обработанной и исходной нефти показывает наличие влияния СВЧ обработки на сохранение текучести нефти при меньших температурах, значение которых зависит от длительности СВЧ обработки и достигает минимального значения через 1,5 минуты.

Подождав пока нефть остынет до $50{ }^{\circ} \mathrm{C}$, мы с помощью вискозиметра ВПЖ определили вязкость. Она стала равна 84 сСт. Значит, вязкость уменьшилась в 5,5 раз.

\section{Вывод}

В итоге был получен устойчивый во времени эффект снижения кинематической вязкости и температуры застывания высокобитуминозной нефти, подтверждённый экспериментально. У всех обработанных образцов нефти было обнаружено временное до 10 дней сохранение текучего состояния с достигнутой температурой застывания, которое через $5-7$ дней возвращалось к исходному значению и пропадало, при этом нефть возвращалась в исходное состояние с температурой застывания более $18^{\circ} \mathrm{C}$.

Таким образом, 1,5-минутная СВЧ обработка высокобитуминозной нефти с мощностью излучения 900 Вт приводит:

a) к временному (до 3-х дней) понижению температуры застывания нефти не выше $0{ }^{\circ} \mathrm{C}$;

б) снижению вязкости в 5,5 раз.

В скором будущем, когда запасы маловязких подойдут к концу и огромное внимание будет уделено добычи высоковязких нефтей, то возможно именно этот метод снижения вязкости будет основополагающим при транспортировке и добычи нефти.

\section{ЛИТЕРАТУРА}

1. Окресса, Э. Применение энергии сверхвысоких частот в промышленности / Э. Окресса. - М.: Мир, 1971. $-272 \mathrm{c}$.

2. Микроволновое излучение и интенсификация химических процессов / Д. Л. Рахманкулов, И. Х. Бикбулатов, Н. С. Шулаев, С. Ю. Шавшукова. - М.: Химия, 2003. - 220 с.

3. Гетерогенно-каталитические промышленные процессы под действием электромагнитного излучения СВЧ диапазона / Р. Р. Даминев, И. Х. Бикбулатов, Н. С. Шулаев, Д. Л. Рахманкулов. - М.: Химия, 2006. $134 \mathrm{c}$. 